\title{
AETIOLOGY AND OUTCOME OF PAEDIATRIC ACUTE KIDNEY INJURY IN A TERTIARY HOSPITAL IN EASTERN INDIA
}

\author{
Kripa Nath Mishra1, Yogalakshmi Sivaprakasam²
}

${ }^{1}$ Associate Professor and HOD, Department of Paediatrics, Darbhanga Medical College and Hospital, Laheriasarai, Bihar. 2Postgraduate Student, Department of Paediatrics, Darbhanga Medical College and Hospital, Laheriasarai, Bihar.

\begin{abstract}
BACKGROUND
ABSTRACT

Acute kidney injury is an important cause of mortality and morbidity in children. The aetiology varies between countries and the incidence is in increasing trend. In developing countries, there is difficulty in providing dialysis which affects the outcome of AKI. The purpose of the study was to describe the aetiology and outcome of acute kidney injury in 1 month to 12 years children admitted in children ward and PICU of a tertiary hospital.
\end{abstract}

\section{MATERIALS AND METHODS}

The study was done by retrospective analysis of medical records of 4320 children admitted in children's ward and PICU of a tertiary hospital over a period of one year from July 2016 to June 2017.

\section{RESULTS}

Among 4320 children admitted, we had 88 cases of AKI with a prevalence of 20.3 per 1000 admitted children. Mean age was $5.53 \pm 3.93$ years with a range of 38 days to 12 years. $87.5 \%$ cases were community acquired. Intrinsic renal $\mathrm{AKI}(52.2 \%, \mathrm{n}=46) \mathrm{was}$ the major mechanism. Gastroenteritis $(33 \%, n=29)$ and AGN $(10.2 \%, n=9)$ were the common aetiologies. Severity of AKI measured according to pRIFLE criteria showed the proportion of children in the categories of risk, injury and failure were almost equal. Mortality was $11.7 \%$, about half occurring in children in whom dialysis was not provided due to technical issues.

\section{CONCLUSION}

This study concluded that prevalence of AKI is increasing. Gastroenteritis was the most important cause. Mortality can be reduced with better access to dialysis.

\section{KEYWORDS}

Acute Kidney Injury, RIFLE, Paediatrics.

HOW TO CITE THIS ARTICLE: Mishra KN, Sivaprakasam Y. Aetiology and outcome of paediatric acute kidney injury in a tertiary hospital in Eastern India. J. Evolution Med. Dent. Sci. 2018;7(13):1659-1662, DOI: 10.14260/jemds/2018/374

\section{BACKGROUND}

Acute kidney injury (AKI) formerly known as acute renal failure is defined as a sudden deterioration in renal function resulting in the inability of kidney to maintain fluid and electrolyte homeostasis. The epidemiology of AKI varies between developed and developing countries.[1] AKI in developed world is mainly hospital acquired, whereas in developing countries community acquired AKI predominates.[1,2] The incidence of AKI in hospitalised children is increasing, ${ }^{[3]}$ particularly in paediatric intensive care units (PICU). There has been a dramatic change in the aetiology of paediatric AKI. Experience in single-centre studies from 1980 to 1990 showed HUS, primary renal disease and sepsis as the main causes for paediatric AKI.[4,5] But studies done later showed renal ischaemia, nephrotoxins and sepsis as the major causes.[3,6]

'Financial or Other Competing Interest': None.

Submission 09-02-2018, Peer Review 07-03-2018,

Acceptance 13-03-2018, Published 26-03-2018.

Corresponding Author:

Dr. Yogalakshmi Sivaprakasam,

Room No. 67, New PG Girls Hostel,

DMCH Campus, Laheriasarai-846003,

Bihar.

E-mail: yogalakshmi1988@gmail.com

DOI: $10.14260 /$ jemds/2018/374

\section{(c) $(\mathrm{P})($}

These entities as an isolated cause results in better prognosis than AKI following multiorgan failure. But in developing countries due to delayed access to renal replacement therapy, these causes contribute to significant morbidity and mortality.[7,8,9] Our aim was to describe the aetiology and outcomes of paediatric AKI in a tertiary teaching hospital in Eastern India, so that better resources can be planned and allotted for early intervention in children with AKI.

\section{MATERIALS AND METHODS}

The study was conducted as a retrospective descriptive study in the children ward and PICU of Department of Paediatrics in a tertiary teaching hospital of Eastern India from July 2016 to June 2017 over a period of one year. This hospital is the major Government Sector Hospital in Northern Bihar. The study was approved by Ethical Committee of the College. As the study was done on previously available records, consent was not taken. Data was collected by reviewing the medical records of all patients in the age group of one month to 12 years, who were admitted in the children ward and PICU from July 2016 to June 2017. All records with a diagnosis of AKI were retrieved and analysed. Records of children who had structural congenital malformations, genetic metabolic disease and known chronic kidney disease were excluded from the study. Serum creatinine was routinely done during admission. The diagnosis of AKI was based on the pRIFLE criteria, i.e. urine output $<0.5 \mathrm{~mL} / \mathrm{kg} /$ hour for greater than 8 hours and/ or if the estimated creatinine clearance (eCCl) 
decreased by $25 \%$ or more. ${ }^{[10]}$ If the previous eCCl of the patient was unavailable, eCCl of $100 \mathrm{~mL} / \mathrm{min} / 1.73 \mathrm{~m}^{2}$ was assumed to be the baseline value. The pattern and severity of AKI was categorised by using pRIFLE criteria as risk (R), injury (I), failure (F) and loss (L) [Table 1]. Patient outcome was reported on hospital discharge or death. For those patients who got discharged, renal outcomes at 3 months post-discharge were analysed from the follow-up records. Complete renal recovery was defined as normalisation of symptoms and indicators of AKI within 12 weeks. Partial recovery as persistence of renal abnormalities without the need of dialysis in those who were receiving dialysis.

\begin{tabular}{|c|c|c|}
\hline Criteria & Estimated CCl & Urine Output \\
\hline Risk & eCCl decreased by $25 \%$ & $\begin{array}{c}<0.5 \mathrm{~mL} / \mathrm{kg} / \mathrm{hour} \text { for } 8 \\
\text { hours }\end{array}$ \\
\hline Injury & eCCl decreased by $50 \%$ & $\begin{array}{c}<0.5 \mathrm{~mL} / \mathrm{kg} / \mathrm{hour} \text { for } \\
16 \text { hours }\end{array}$ \\
\hline Failure & $\begin{array}{c}\mathrm{eCCl} \text { decreased by } 75 \% \text { or } \\
\mathrm{eCCl}<35 \mathrm{~mL} / \mathrm{min} / 1.73 \mathrm{~m}^{2}\end{array}$ & $\begin{array}{c}<0.3 \mathrm{~mL} / \mathrm{kg} / \mathrm{hour} \text { for } \\
24 \text { hours or } \\
\text { Anuria for } 12 \text { hours }\end{array}$ \\
\hline Loss & $\begin{array}{c}\text { Persistent failure }>4 \\
\text { weeks }\end{array}$ & \\
\hline $\begin{array}{c}\text { End- } \\
\text { Stage }\end{array}$ & $\begin{array}{c}\text { End-stage renal disease } \\
\text { (persistent failure }>3 \\
\text { months) }\end{array}$ & \\
\hline \multicolumn{2}{|c|}{ Table 1. Paediatric Modified RIFLE (pRIFLE) Criteria[10] } \\
\hline
\end{tabular}

A detailed and relevant clinical history and examination of the admitted children were noted in the medical records. At admission all children got a complete blood count, blood urea, serum creatinine and urine analysis including microscopy if the child was having urine output. Serum electrolytes, urea and creatinine was repeated as required after the diagnosis of AKI was made. Urine sodium, fractional excretion of sodium, serology for Hepatitis B and Hepatitis C was done if necessary. HIV was done if parents consented. Blood smear for malaria was done in cases of fever. Peripheral blood smear, anti-nuclear antibody and anti-dsDNA were done if indicated. Ultrasound examination of the kidneys, ureter and bladder was done in all children when AKI was suspected.

There is no separate Paediatric Nephrology Unit, but the children requiring dialysis were managed in adult dialysis units with haemodialysis.

\section{Children Underwent Dialysis if any one of the following} was Present-

1. Anuria despite medical therapy.

2. Volume overload with evidence of hypertension and/ or pulmonary oedema, refractory to diuretic therapy.

3. Severe hyperkalaemia $>7.0 \mathrm{mmol} / \mathrm{L}$.

4. Severe metabolic acidosis, unresponsive to medical management.

5. Uraemia (encephalopathy, pericarditis, neuropathy) and seizures.

6. Blood urea nitrogen $>100-150 \mathrm{mg} / \mathrm{dL}$.
The following Definitions were used to determine the Aetiologies of AKI

i. Pre-renal AKI was diagnosed from the history and risk factors leading to hypovolaemia or decrease in effective circulating volume with absence of kidney damage, normal urinary indices and when AKI was reversible with restoration of haemodynamic abnormality.

ii. Intrinsic-renal AKI was diagnosed with history or risk factors leading to renal parenchymal damage including renal vascular, microvascular, glomerular diseases, AIN as well as ATN with abnormal urinary indices like FENa $>1 \%$, urine sodium $>30 \mathrm{mEq} / \mathrm{L}$, urine osmolality $<350 \mathrm{mOsm} / \mathrm{kg}$ and/or red cell casts.

iii. Post-renal AKI was diagnosed when there was acute bilateral urinary tract obstruction or obstruction of the urinary tract of a solitary kidney and when AKI improved after relieving the obstruction.

iv. Sepsis is defined as systemic inflammatory response syndrome (presence of abnormal temperature > $38.5^{\circ} \mathrm{C}$ or $<36^{\circ} \mathrm{C}$ or abnormal leukocyte count for age or $>10 \%$ immature neutrophils with tachycardia or tachypnoea) plus a suspected or proven infection.

v. HUS was diagnosed when there is triad of microangiopathic haemolytic anaemia, thrombocytopaenia and acute renal insufficiency.

Mean and median was calculated as appropriate for continuous variables and percentage and proportion was used to describe categorical variables. Data was analysed using SPSS 22 software.

\section{RESULTS}

From July 2016 to June 2017 over a period of one year, 4320 children aged one month to 12 years were admitted in the children ward and PICU of Department of Paediatrics. Of these, the hospital records of 88 children had AKI. This gives a prevalence of $20.3 \mathrm{AKI}$ per 1000 hospitalised children. The mean age of the children with AKI was $5.53 \pm 3.93$ years with a range of 38 days to 12 years. Of these 24 children were admitted in PICU and 64 were admitted in children ward. Of the 88 children with AKI 13 (14.8\%) were infants, 33 (37.5\%) were above 1 year to 5 years and $22(47.7 \%)$ were above 5 years to 12 years. Male-to-female ratio was 1.2: 1 .

Community acquired AKI was more common, 77 (87.5\%) than hospital acquired AKI 11 (12.5\%) [Table 2]. Intrinsic renal AKI accounted for most cases $(52.2 \%, n=46)$, in which acute tubular necrosis being the main clinical form $(43.5 \%$, $\mathrm{n}=20)$ followed by glomerulonephritis $(23.9 \%, \mathrm{n}=11)$. Prerenal mechanism was responsible in $37(42 \%)$ cases [Table3]. Gastroenteritis $(33 \%, n=29)$ was the most common aetiology of AKI followed by AGN (10.2\%, $n=9)$. Drug induced AKI and sepsis contributed $5.7 \%(n=5)$ of AKI cases each [Table 4].

\begin{tabular}{|c|c|c|}
\hline Type of AKI & Frequency & Percent \\
\hline Community acquired & 77 & 87.5 \\
\hline Hospital acquired & 11 & 12.5 \\
\hline Total & $\mathbf{8 8}$ & $\mathbf{1 0 0 . 0}$ \\
\hline \multicolumn{2}{|c|}{ Table 2. Type of AKI } \\
\hline
\end{tabular}




\begin{tabular}{|c|c|c|}
\hline Mechanism of AKI & Frequency & Percent \\
\hline Pre-renal & 37 & 42 \\
\hline Intrinsic renal & 46 & 52.2 \\
\hline Vascular & 7 & 8.0 \\
\hline GN & 11 & 12.5 \\
\hline ATN & 20 & 22.7 \\
\hline AIN & 3 & 3.4 \\
\hline Unknown & 5 & 5.7 \\
\hline Post-renal & 5 & 5.7 \\
\hline Total Table 3. Mechanism of AKI \\
\hline \multicolumn{2}{|c}{} \\
\hline
\end{tabular}

\begin{tabular}{|c|c|c|}
\hline Aetiology of AKI & Frequency & Percent \\
\hline Gastroenteritis & 29 & 33.0 \\
\hline Cardiac causes & 2 & 2.3 \\
\hline Sepsis & 5 & 5.7 \\
\hline Malaria & 1 & 1.1 \\
\hline Pyelonephritis & 4 & 4.5 \\
\hline HIV & 2 & 2.3 \\
\hline AGN & 9 & 10.2 \\
\hline Drugs & 5 & 5.7 \\
\hline HUS & 4 & 4.5 \\
\hline Nephrotic syndrome & 2 & 2.3 \\
\hline SLE & 1 & 1.1 \\
\hline Blood transfusion & 3 & 3.4 \\
\hline Lithiasis & 2 & 2.3 \\
\hline Neurogenic bladder & 1 & 1.1 \\
\hline HSP & 2 & 2.3 \\
\hline VUR & 2 & 2.3 \\
\hline MODS & 4 & 4.5 \\
\hline Drowning & 2 & 2.3 \\
\hline DKA & 4 & 4.5 \\
\hline RPGN & 1 & 1.1 \\
\hline Burns & 3 & 3.4 \\
\hline Total & $\mathbf{8 8}$ & $\mathbf{1 0 0 . 0}$ \\
\hline Table 4. Aetiology of AKI \\
\hline \multicolumn{2}{|l}{} \\
\hline
\end{tabular}

According to pRIFLE criteria severity of AKI was almost equal in risk $(35.2 \%, \mathrm{n}=31)$, injury $(31.8 \%, \mathrm{n}=28)$ and failure $(33 \%, n=29)$ category [Table 5]. Dialysis was essential in 20 $(22.7 \%)$. But only $60 \%(n=12)$ cases in whom dialysis was indicated received dialysis. The reason for inability to access dialysis was lack of appropriate material $(n=3)$, inability to shift to haemodialysis unit as patients were unstable requiring emergency intensive care $(n=2)$ and short duration of hospitalisation with unstable vitals leading to death $(n=3)$.

\begin{tabular}{|c|c|c|}
\hline Severity of AKI & Frequency & Percent \\
\hline Risk & 31 & 35.2 \\
\hline Injury & 28 & 31.8 \\
\hline Failure & 29 & 33.0 \\
\hline Total & $\mathbf{8 8}$ & $\mathbf{1 0 0 . 0}$ \\
\hline Table 5. Severity according to pRIFLE Criteria \\
\hline
\end{tabular}

Three children were discharged against medical advice, 8 children were referred to higher centre either for urological intervention or when there was no appropriate material for patients requiring dialysis. Among the remaining 77 patients treated for AKI, 9 children died with a disease specific mortality of $11.7 \%$ at 3 months follow-up $74 \%$ ( $n=57)$ had complete recovery, $11.7 \%(n=9)$ had partial recovery and $2.6 \%(n=2)$ were lost for follow-up [Figure 1]. Mortality was higher in AKI children with intrinsic renal injury. Both the cases of post-renal injury who refused referral for urological intervention, one was treated conservatively and the other who had haemodialysis had only partial recovery [Figure 2].

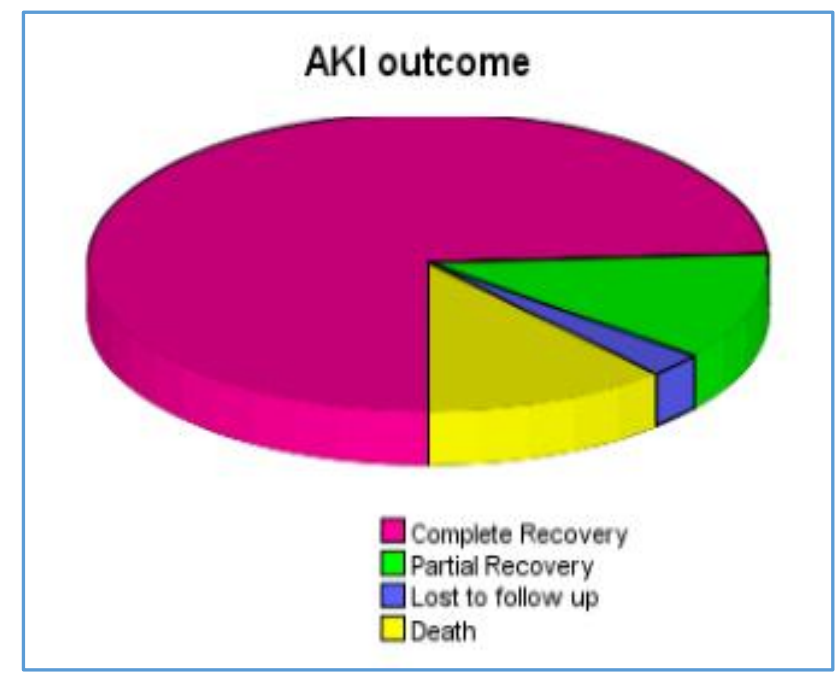

Figure 1. Outcome of AKI

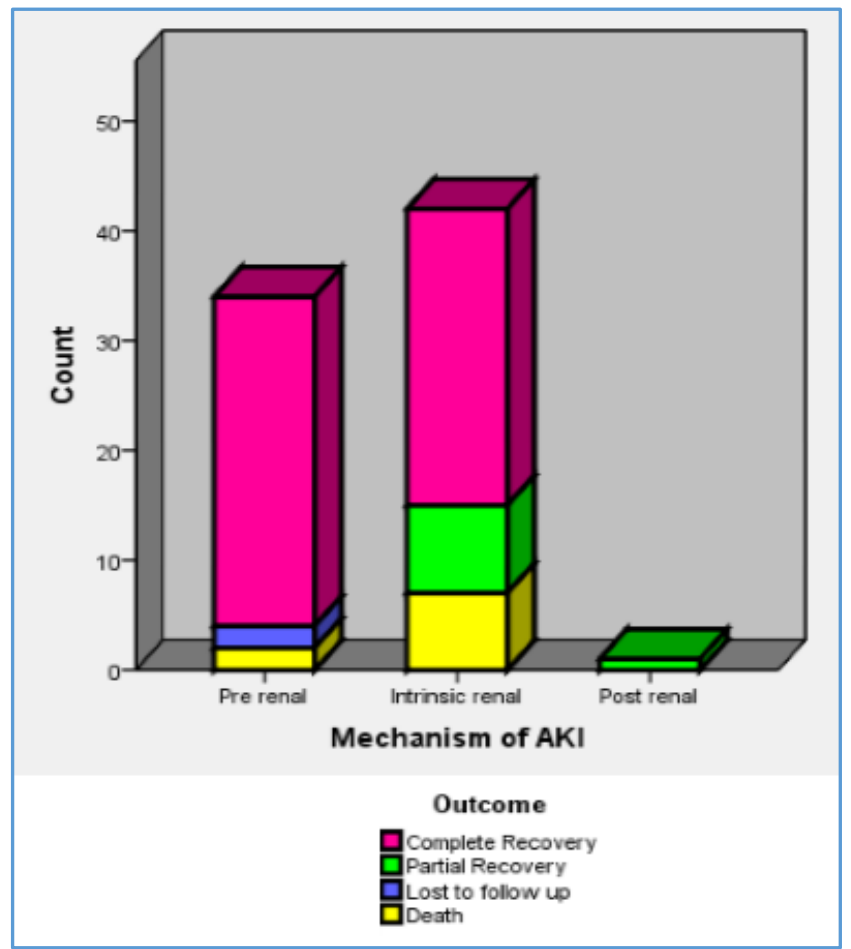

Figure 2. Outcome according to Mechanism of AKI

\section{DISCUSSION}

The present study described AKI in children of one month to 12 years admitted to the children ward and PICU of a tertiary teaching hospital in Eastern India over a period of one year. AKI was defined using pRIFLE criteria and the prevalence was found to be 20.3 AKI per 1000 admitted children. The rising prevalence of AKI has been described both in developed[3] and developing countries.[11] The present study also confirmed the rising trend in prevalence of AKI when compared to previous studies done in Eastern India.[11] But this can also be because of the difference in criteria used to define AKI. The prevalence in the present study correlated with a recent study conducted in Nigeria.[12]

Being a tropical country where the prevailing climatic conditions favour spread of tropical infectious diseases, the 
community acquired AKI (87.5\%) was higher.[13] Intrinsic renal injury (52.2\%) due to ATN was the major mechanism of AKI in comparison with studies done in Nigeria,[12] which also used pRIFLE criteria for defining AKI. Although, aetiology of AKI is changing and the proportion of diarrhoea associated AKI had significantly decreased in some studies,[11] the present study showed gastroenteritis was the most common cause of AKI (33\%) followed by acute glomerulonephritis $(10.2 \%)$ which correlated with studies of Krishnamurthy S et al[14] and Agarwal et al.[15] Though gastroenteritis was the main aetiology of AKI in the present study, the proportion of gastroenteritis induced AKI had decreased because of the increasing use of oral rehydration solution in the primary health centre. Hypovolaemia and post-streptococcal acute glomerulonephritis were among the important causes in Thailand, ${ }^{[3]}$ although sepsis and infections are evolving as the major causes.[3,14]

The severity of AKI as risk (35.2\%), injury (31.8\%) and failure $(33 \%)$ is in agreement with the study done in PICU by Naik S et al.[16] Lack of appropriate material for dialysis was the hurdle faced in children younger than 5 years to do haemodialysis. But $60 \%$ of patients had access to dialysis, which is better than in some developing countries.[17] As the study was conducted in a Government Sector Hospital, financial constraints were not the factor for inability to access dialysis.

Mortality in AKI patients were $11.7 \%(n=9)$. As more than half $(n=5)$ of mortality occurred in children who needed dialysis but was not given due to technological issues, nonavailability of haemodialysis inside PICU and peritoneal dialysis was not practiced here. These areas of resource limitation should be improved to decrease mortality. As in the study done in China, intrinsic renal AKI had the highest mortality.[18]

\section{CONCLUSION}

The present study concluded that the prevalence of AKI is increasing in Eastern India. Community acquired AKI accounted for majority of cases, gastroenteritis being the main aetiology, but in declining trend. AKI related mortality may be reduced if access to dialysis can be improved by addressing technical issues.

\section{Abbreviations \\ AKI- Acute Kidney Injury, PICU- Paediatric Intensive Care Unit, pRIFLE- Paediatric Risk, Injury, Failure, Loss, End-stage disease, eCCl- Estimated Creatinine Clearance, FENa- Fractional Excretion of sodium, AGN- Acute Glomerulo- Nephritis, GN- Glomerulo-Nephritis, ATN- Acute Tubular Necrosis, AIN- Acute Interstitial Nephritis, HUS- Haemolytic Uraemic Syndrome, HIV- Human Immunodeficiency Virus, SLE- Systemic Lupus Erythematosus, DKA- Diabetic Keto- Acidosis, RPGN- Rapidly Progressive Glomerulo-Nephritis, VUR- Vesico-Ureteric Reflux, MODS- Multi-Organ Dysfunction Syndrome.}

\section{REFERENCES}

[1] Cerda J, Bagga A, Kher V, et al. The contrasting characteristics of acute kidney injury in developed and developing countries. Nat Clin Pract Nephr 2008;4(3):138-53.
[2] Jha V, Parameswaran S. Community acquired acute kidney injury in tropical countries. Nat Rev Nephrol 2013;9(5):278-90.

[3] Vachvanichsanong P, Dissaneewate P, Lim A, et al Childhood acte renal failure: 22-year experience in an university hospital in southern Thailand. Pediatrics 2006;118(3):e786-e91.

[4] Andreoli SP. Acute renal failure. Curr Opin Pediatr 2002;14(2):183-8.

[5] Flynn JT. Choice of dialysis modality for management of pediatric acute renal failure. Pediatr Nephrol 2002;17(1):61-9.

[6] Ball EF, Kara T. Epidemiology and outcome of acute kidney injury in New Zealand children. J Paediatr Child Health 2008;44(11):642-6.

[7] Anochie IC, Eke FU. Acute renal failure in Nigerian children: Port Harcourt experience. Pediatr Nephrol 2005;20(11):1610-4.

[8] Hui-Stickle S, Brewer ED, Goldstein SL. Pediatric ARF epidemiology at a tertiary care centre from 1999 to 2001. Am J Kidney Dis 2005;45(1):96-101.

[9] Bailey D, Phan V, Litalien C, et al. Risk factors of acute renal failure in critically ill children: a prospective descriptive epidemiological study. Pediatr Crit Care Med 2007;8(1):29-35.

[10] Akcan-Arikan A, Zappitelli M, Loftis LL, et al. Modified RIFLE criteria in critically ill children with acute kidney injury. Kidney Int 2007;71(10):1028-35.

[11] Prakash J, Singh TB, Ghosh B, et al. Changing epidemiology of community-acquired acute kidney injury in developing countries: Analysis of 2405 cases in 26 years from eastern India. Clin Kidney J 2013;6(2):150-5.

[12] Esezobor CI, Ladapo TA, Osinaike B, et al. Paediatric acute kidney injury in a tertiary hospital in Nigeria: Prevalence, causes and mortality rate. PLoS One 2012;7(12):e51229.

[13] Jha V, Malhotra HS, Sakhuja V, et al. Spectrum of hospital-acquired acute renal failure in the developing countries-Chandigarh study. Q J Med 1992;83(303):497-505.

[14] Krishnamurthy S, Mondal N, Narayanan P, et al. Incidence and etiology of acute kidney injury in southern India. Indian J Pediatr 2013;80(3):183-9.

[15] Agarwal I, Kirubakaran C, Markandeyulu V. Clinical profile and outcome of acute renal failure in South Indian children. J Ind Med Assoc 2004;102(7):353-4, 356.

[16] Naik S, Sharma J, Yengkom R, et al. Acute kidney injury in critically ill children: risk factors and outcomes. Indian J Crit Care Med 2014;18(3):129-33.

[17] Fouda H, Ashuntantang G, Halle MP, et al. The epidemiology of acute kidney injury in a tertiary hospital in Cameroon: a 13 months review. J Nephrol Ther 2016;6:250.

[18] Cao Y, Yi ZW, Zhang H, et al. Etiology and outcomes of acute kidney injury in Chinese children: a prospective multicentre investigation. BMC Urology 2013;13:41. 